\title{
Problemática da Ocorrência de Diferentes espécies de Capim- Colchão (Digitaria spp.) NA CUltura da CANA-DE-AÇÚCAR ${ }^{1}$
}

\author{
Understanding the Occurrence of Different Species of Crabgrass (Digitaria spp.) in \\ Sugar Cane Crop
}

\begin{abstract}
DIAS, A.C.R. ${ }^{2}$, CARVALHO, S.J.P. ${ }^{3}$, NICOLAI, M. ${ }^{4}$ e CHRISTOFFOLETI, P.J. ${ }^{5}$
RESUMO - O gênero Digitaria inclui cerca de 300 espécies de plantas, distribuídas em regiões tropicais e subtropicais de ambos os hemisférios. No Estado de São Paulo, esse gênero contém 13 espécies descritas, nas quais a diferenciação visual torna-se dificil de ser feita no campo, devido à grande semelhança morfológica entre elas. As espécies Digitaria nuda, $D$. ciliaris, $D$. horizontalis e $D$. bicornis, conhecidas popularmente por capim-colchão, são plantas daninhas comumente encontradas em áreas de produção de cana-de-açúcar do Estado de São Paulo. Na prática, produtores têm relatado casos de falhas de controle em áreas de cana-de-açúcar, que possivelmente estão relacionadas com mudanças da flora infestante em função da seleção de algumas espécies de capim-colchão tolerantes aos herbicidas anteriormente recomendados para o seu controle. Suspeita-se que essas populações selecionadas são constituídas por diferentes espécies de capim-colchão, porém $D$. nuda é a que apresenta maiores niveis de tolerância a alguns produtos. A compreensão da dinâmica populacional de espécies de plantas daninhas do gênero Digitaria, bem como dos mecanismos de tolerância delas a alguns grupos de herbicidas, auxilia nas recomendações de manejo, evitando ou retardando o aparecimento do fenômeno. Ainda, a identificação das espécies ocorrentes nas áreas produtoras de cana-de-açúcar é uma ferramenta que proporciona a correta escolha do herbicida de acordo com a espécie infestante, o que aumenta as chances de sucesso de controle.
\end{abstract}

Palavras-chave: Digitaria spp., tolerância, seleção, cana-de-açúcar, plantas daninhas.

\begin{abstract}
Digitaria genus includes around 300 plant species, distributed in the tropical and subtropical regions of both hemispheres. Thirteen described species occur in the state of Sao Paulo, Brazil, with visual differentiation being difficult to be made in the fields due to their great morphological similarity. The species Digitaria nuda, D. ciliaris, D. horizontalis and D. bicornis, popularly known as crabgrass, are weeds commonly found in the sugar cane production fields in São Paulo. Cases of cab grass control failure have been reported by producers, likely related with weed community changes as a result of the selection of some crabgrass species tolerant to herbicides previously recommended for their control. It has been suspected that these selected populations are constituted by different crabgrass species, notably D. nuda, which has higher tolerance levels to some products. Understanding the dynamics of the weed species Digitaria genus (crabgrass) population and its mechanisms of tolerance to some herbicide groups will help outline management recommendations for these weeds, avoiding or delaying their manifestation. Identifying the species that occur in sugar cane producing areas will promote the correct herbicide choice, according to the infesting species, thus increasing the chances of successful control.
\end{abstract}

Keywords: Digitaria spp., tolerance, selection, sugar cane, weeds.

Recebido para publicação em 26.7.2006 e na forma revisada em 11.4.2007.

2 Eng ${ }^{\circledR}-A g r$ r , aluna do curso de Pós-Graduação em Fitotecnia da ESALQ/USP, <acrdias@ esalq.usp.br>; ${ }^{3}$ Mestre em Fitotecnia da ESALQ/USP, <sjpcarvalho @yahoo.com.br>; ${ }^{4}$ Eng o-Agro, aluno do curso de Doutorado em Fitotecnia da ESALQ/USP,

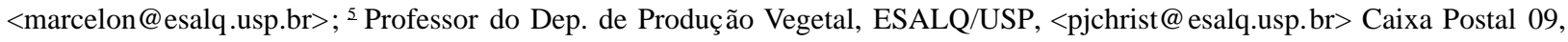
13419-900, Piracicaba, SP. 


\section{INTRODUÇÃO}

Atualmente, a área mundial cultivada com a cultura da cana-de-açúcar (Saccharum spp.) atinge cerca de 19,5 milhões de hectares. Dentre os países produtores, o Brasil é o que possui a maior área, cerca de 5 milhões de hectares, seguido por Índia $(4,1 \mathrm{milhões})$, China (1,3 milhão) e Cuba (1 milhão de hectares cada). No Brasil, a maior região produtora é a Sudeste, que participa com $62 \%$ da área total plantada (somente o Estado de São Paulo contribui com $52 \%$ dessa área), seguida pela região Nordeste, com $21 \%$ da área total. Nessas duas regiões, a produtividade média é de 78 e $55 \mathrm{t} \mathrm{ha}^{-1}$, respectivamente (FNP, 2006).

Entre os principais fatores bióticos presentes no agroecossistema da cana-de-açúcar que têm a capacidade de interferir no desenvolvimento e na produtividade da cultura encontram-se as plantas daninhas (Kuva et al., 2003). A interferência negativa resultante da presença dessas plantas pode causar reduções na quantidade e na qualidade do produto colhido e diminuir o número de cortes viáveis, além de aumentar os custos em cerca de 30\% para cana-soca e de 15 a $20 \%$ para cana-planta (Lorenzi, 1988, 1995; Procópio et al., 2004).

A interferência das plantas daninhas é influenciada por fatores ligados à cultura (espécie ou variedade, espaçamento e densidade de plantio), à época e extensão do periodo de convivência e, também, aos fatores característicos das próprias plantas daninhas (composição específica, densidade e distribuição) (Pitelli, 1985). Entre as principais espécies de plantas daninhas que infestam os canaviais brasileiros encontram-se aquelas conhecidas popularmente como capim-colchão (Digitaria spp.).

A aplicação rotineira de herbicidas gera pressão de seleção sobre a flora infestante, e as duas principais formas de resposta das plantas daninhas são a mudança específica na flora, por meio da seleção de espécies de plantas daninhas mais tolerantes, ou seleção intraespecífica de biótipos resistentes aos herbicidas (Christoffoleti \& Caetano, 1998).

A tolerância de plantas daninhas a herbicidas é resultado da capacidade inata da espécie em suportar aplicações de herbicidas, nas doses recomendadas, sem alterações marcantes em seu crescimento e/ou desenvolvimento. A suscetibilidade também é uma característica inata de uma espécie. Nesse caso, há alterações com efeitos marcantes no crescimento e desenvolvimento da planta, como resultado de sua incapacidade de suportar a ação do herbicida (Christoffoleti, 2000).

Já a resistência de plantas daninhas a herbicidas pode ser definida como a ocorrência natural da habilidade hereditária de alguns biótipos de plantas daninhas, dentro de uma população, que são capazes de sobreviver a um tratamento herbicida que, sob condições normais de uso, controlaria efetivamente esta população de plantas daninhas. A resistência não é uma característica comum inerente à população, mas foi selecionada por pressão de seleção (Oliveira Jr. \& Constantin, 2001).

Na prática, produtores têm relatado casos de falhas de controle em áreas de cana-de-açúcar, que possivelmente estão relacionadas com mudanças da flora infestante em razão da seleção de algumas espécies de capim-colchão tolerantes aos herbicidas anteriormente recomendados para seu controle. Essas populações de capim-colchão são constituídas por diferentes espécies que apresentam niveis maiores de tolerância aos herbicidas, notadamente D. nuda. Assim, os objetivos desta revisão foram diferenciar as espécies de Digitaria spp. infestantes da cultura da cana-de-açúcar e propor alternativas para que o controle seja otimizado.

\section{BIOLOGIA E DIFERENCIAÇÃO DAS ESPÉCIES DO GÊNERO Digitaria}

O gênero Digitaria incluí cerca de 300 espécies de plantas, distribuídas em regiões tropicais e subtropicais de ambos os hemisférios (Canto-Dorow, 2001a). O Brasil é o país das Américas com maior número de espécies de Digitaria, apresentando 26 nativas, das quais nove exclusivas, e mais 12 exóticas. A riqueza específica nas regiões Sul, Sudeste, CentroOeste e Nordeste é mais ou menos equivalente, havendo decréscimo expressivo na região Norte. Nessas regiões, as espécies habitam formações geralmente abertas, como campos naturais e cerrados, sendo comum em locais alterados pelo homem. Algumas espécies têm sido utilizadas como forragem, outras se 
destacam por serem plantas daninhas de culturas (Canto-Dorow \& Longhi-Wagner, 2001).

Somente no Estado de São Paulo foram identificadas 13 espécies, algumas das quais muito parecidas entre si; as suas características diferenciais não se encontram de forma constante, havendo tipos intermediários, que mesmo pessoas especializadas em taxonomia têm dificuldades em classificá-las. Ocorre um complexo de plantas do gênero Digitaria no Brasil, com diferenciação visual em campo bastante difícil; o nome vulgar capim-colchão é aplicado indistintamente, valendo mais os hábitos regionais do que uma definição em nivel de espécie (Kissmann, 1997).

Essas plantas são altamente agressivas como infestantes, sendo relatadas como problema em 60 países, infestando mais de 30 culturas de importância econômica. No Brasil, constituem problema sério em muitas culturas de primavera e verão. Essas espécies são particularmente hábeis no processo de competição, causando danos em culturas anuais e em viveiros. Também apresentam vantagens em relação às culturas em condição de seca, além de apresentarem efeitos alelopáticos sobre várias plantas cultivadas (Kissmann, 1997).

O gênero Digitaria pertence à família Poaceae (Gramineae), subfamília Panicoidaea, tribo Paniceae (Kissmann, 1997). As espécies encontradas no Estado de São Paulo são: $D$. corynottricha, D. neesiana, D. insularis, $D$. eriantha, $D$. fuscescens, $D$. connivens, $D$. sejunta, $D$. filiformis, $D$. violascens, $D$. horizontalis, D. bicornis, $D$. sanguinalis e D. ciliaris (Canto-Dorow, 2001a), além de
D. nuda (são 14 espécies neste Estado, e não 13, como foi dito anteriormente), que foi citada pela primeira vez em áreas cultivadas com cana-de-açúcar (Dias et al., 2003). Dentre essas espécies, D. horizontalis, D. ciliaris, $D$. bicornis e $D$. nuda são encontradas comumente como plantas daninhas em lavouras de cana-de-açúcar do Estado de São Paulo (Lorenzi, 2000a; Dias et al., 2003).

A identificação taxonômica das espécies do gênero Digitaria só é possivel com utilização de uma lente de aumento de no mínimo 25 vezes, sendo realizada, principalmente, com base nas características morfológicas da espigueta (Kissmann, 1997; Dias, 2004). As espiguetas são elementos de suma importância para a diferenciação das espécies, a começar por sua forma de inserção, seguindo pelo formato, pelo desenho da gluma II e da lema estéril, bem como pela pilosidade; devem ser observadas na fase de maturação (algumas iniciando a maturação e outras já maduras) (Canto-Dorow, 2001b).

$D$. horizontalis, D. nuda, D. ciliaris e $D$. sanguinalis são muito parecidas morfologicamente e, no campo, dificilmente podem ser diferenciadas. $D$. ciliaris e $D$. sanguinalis diferenciam-se de $D$. horizontalis por não apresentarem pêlos de base tuberculada sobre a raque. $D$. ciliaris e $D$. sanguinalis diferenciam-se também pelo maior tamanho das espiguetas (Cavalheiro \& Barreto, 1981). Para correta identificação das espécies de capim-colchão, sugere-se a adoção da chave de identificação das espécies de Digitaria para o Estado de São Paulo, proposta por Canto-Dorow (2005), em que:

1. Presença de tricomas na ráquis 2

1'. Ausência de tricomas na ráquis. 3

2. Gluma I ausente; tricomas ultrapassando o ápice da lema I. D. nuda

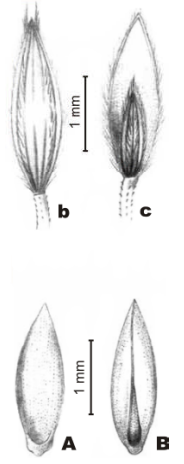

a. espigueta, vista dorsal, sem gluma inferior;

b. espigueta, vista ventral, com gluma superior.

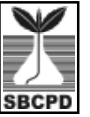

Planta Daninha, Viçosa-MG v. 25, n. 2, p. 489-499, 2007 
2'. Gluma I presente; tricomas não ultrapassando o ápice da lema I

D. horizontalis

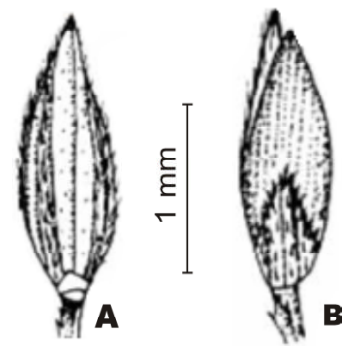

$\alpha$. (A) espigueta, vista dorsal, com gluma inferior na base;

$\beta$. (B) espigueta, vis ta ventral, com gluma superior.

3. Gluma I presente

3. Gluma I ausente.

D. nuda

4. Indumento igual nas espiguetas, somente tricomas macios nas margens .5

5. Nervuras lisas na lema I, gluma II $1 / 2$ a $3 / 4$ do comprimento da lema II; lígula de $1,53 \mathrm{~mm}$ de comprimento

D. ciliaris
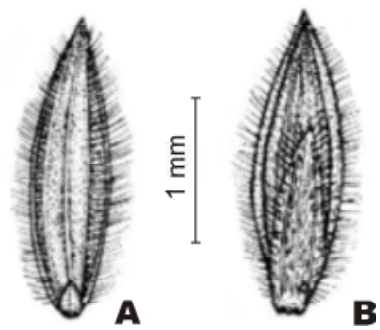

a. espigueta, vista dorsal, com gluma inferior na base;

b. espigueta, vista ventral, com gluma superior.

5. Nervuras escabrosas na lema I, gluma II até $1 / 2$ do comprimento da lema II; lígula 0,5-1 mm de comprimento

D. sanguinalis

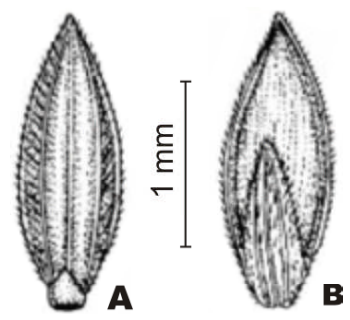

a. espigueta, vista dorsal, com gluma inferior na base;

b. espigueta, vista ventral, com gluma superior.

Na Tabela 1 é apresentado um resumo das características das espécies de capim-colchão utilizadas para a identificação, adaptado de Canto-Dorow (2005).

\section{CARACTERÍSTICAS GERAIS DO GÊNERO Digitaria heist}

São plantas com racemos espiciformes, de raque geralmente triangulada, com ou sem alas laterais. Ao longo da raque ocorrem espiguetas, que podem ser subsésseis ou pedicela- das. É mais comum a ocorrência de espiguetas pareadas, sendo uma subséssil e outra pedicelada. As espiguetas podem ocorrer em tríades, em quatro ou, raramente, isoladas (Kissmann, 1997).

As espiguetas podem ser lanceoladas ou elipticas, comprimidas, quase plano-convexas. São unifloras por ser a flor basal estéril, representada somente por lema, que em algumas espécies pode estar acompanhada da pálea muito reduzida. De um lado da espigueta, voltado para a raque, vê-se a gluma II sobre a lema 
fértil; o comprimento dessa gluma pode ser equivalente ou menor que o comprimento da lema. Do outro lado, voltado para frente no racemo, vê-se a lema estéril e a gluma I, muito reduzida. O número de nervuras na gluma II e na lema estéril pode ser de 3,5 ou 7 . A pilosidade é característica nas espécies, podendo ser reduzida e com pêlos curtos ou abundante, com pêlos curtos ou muito longos. Todos esses - e alguns outros - detalhes são muito importantes para a separação das espécies. Para identificação correta, devem-se tomar racemos com espiguetas em fase de maturação (Kissmann, 1997).

\section{-D. nuda Schumach}

D. nuda ocorre em regiões tropicais de todos os continentes, sendo aparentemente mais abundante na África (Veldkamp, 1973), onde foi originalmente descrita. Ela já havia sido citada para o Rio Grande do Sul por Cavalheiro \& Barreto (1981), sendo considerada adventícia no Estado. Essa espécie ocorre em locais de baixa altitude e é estéril, aparentemente preferindo solos arenosos (Cavalheiro \& Barreto, 1981; Veldkamp, 1973).

D. nuda apresenta espiguetas em número de dois por nó, de $2-4 \mathrm{~mm}$ de comprimento, 0,6-0,7 $\mathrm{mm}$ de largura, lanceoladas; gluma inferior ausente; gluma superior de 0,9-1,2 mm de comprimento, 0,3-0,5 $\mathrm{mm}$ de largura, até $1 / 2$ do comprimento da lema inferior, aguda, pilosa, tricomas agudos, esbranquiçados, esparsos, nas margens e entre as nervuras, ultrapassando o ápice da gluma; lema inferior de 2-2,1 $\mathrm{mm}$ de comprimento, 0,6-0,7 $\mathrm{mm}$ de largura, aguda, pilosa nas margens e entre as nervuras laterais, tricomas agudos, densos, ultrapassando o ápice da lema em 0,2-0,4 mm; pálea inferior ausente; antécio superior de 1,82,2 $\mathrm{mm}$ de comprimento, 0,4-0,6 $\mathrm{mm}$ de largura, com flor bissexuada, lanceolado, agudo, com papilas em fileiras longitudinais, castanhoclaro na maturidade. Pelas dimensões das espiguetas, assemelha-se a $D$. horizontalis, da qual difere por ter gluma inferior e pela lema inferior com tricomas não ultrapassando o seu ápice (Canto-Dorow, 2001b).

\section{- D. horizontalis Willd.}

Planta nativa nas regiões tropicais da América, onde, na costa ocidental, é a espécie mais freqüente de Digitaria. No Brasil é muito comum, sendo predominante na região Sudeste. É uma planta anual reproduzida por semente, alastrando-se por enraizamento a partir de nós dos colmos em contato com o solo. Aprecia solos férteis, cultivados ou não, sendo pouco agressiva em solos pobres. É uma das primeiras infestantes a aparecer após o preparo do solo, na primavera. Encerra o ciclo antes de culturas como soja e milho. Apresenta número de cromossomos $n=18$ (Kissmann, 1997).

Quando isolada ou em espaço aberto, tende a estender os ramos sobre o solo, em todos os sentidos, a partir da base, elevando apenas a parte terminal com a inflorescência. A altura fica geralmente entre 30 e $60 \mathrm{~cm}$. Indumento de curtos pêlos alvos, distendidos, sobre a bainha e, de forma escassa, sobre a fase dorsal das lâminas foliares.

Apresenta espiguetas binadas, lanceoladas, homomorfas, pubescentes, tricomas agudos e esbranquiçados presentes na gluma superior e lema inferior; gluma inferior ausente ou reduzida de até $0,1 \mathrm{~mm}$, aguda; gluma superior de $0,8-1,0 \mathrm{~mm}$, obtusa, atingindo até metade do comprimento da lema inferior; lema inferior de 1,9-2,2 $\mathrm{mm}$, aguda, nervuras laterais glabras, glabro em ambos os lados da nervura central e alternadamente pubescente e glabro nas demais regiões entre as nervuras, margens pubescentes, tricomas não ultrapassando o ápice; antécio superior de 1,9-2,1 mm, castanho-claro na maturação (Canto-Dorow, 2001b).

$\mathrm{Na}$ caracterização da espécie, entre as Digitarias, a $D$. horizontalis se distingue por apresentar nos racemos, junto à base de cada espigueta, um longo pêlo branco de base tuberculada (Kissmann, 1997).

\section{- D. ciliaris (Retz.) Koel.}

Menciona-se que seja originária da ilha de Taiwan (Formosa e que é bastante disseminada pelo sudeste asiático e costa oeste da África). Muito freqüente na América do Sul. No Brasil, é, juntamente com $D$. horizontalis, uma das espécies de capim-colchão mais comuns (Kissmann, 1997).

Planta anual com reprodução por sementes, apresentando número de cromossomos 
Tabela 1 - Resumo das características morfológicas que diferenciam as espécies de plantas daninhas do gênero Digitaria (adaptado de Canto-Dorow, 2005)

\begin{tabular}{|c|c|c|c|c|}
\hline \multirow{2}{*}{ Característica } & \multicolumn{4}{|c|}{ Espécie } \\
\hline & D. ciliaris & D. sanguinalis & D. nuda & D. horizontalis \\
\hline Comprimento da espi gueta $(\mathrm{mm})^{1 / 1}$ & $(2,2) 2,5-3,2(-3,4)$ & $2,5-3,2$ & $2,2-2,4$ & $2-2,2(-2,7)$ \\
\hline Gluma I & Sim & Sim & não & Sim \\
\hline Comprimento da gluma II (mm) & $1,6-2,1$ & $1,3-1,6$ & $0,9-1,2$ & $0,8-1,2$ \\
\hline Tricoma ultrapassando a espigueta & Não & Não & Sim & Não \\
\hline Escabrosidade das nervuras da lema & Não & Sim & Não & Não \\
\hline Tricomas nas ráquis & Não & Não & Sim/Não & Sim \\
\hline Comprimento da lígula (mm) & $1,5-3$ & $0,5-1$ & $0,6-2$ & $1-2$ \\
\hline Distribuição geográfica no Brasil & Brasil & Somente RS & Brasil exceto RS & Brasil exceto RS \\
\hline
\end{tabular}

1/ Os valores numéricos apresentados entre parênteses correspondem às medidas extremas observadas, e os valores encontrados com maior freqüência antecedem estes.

$2 n=27$. Em regiões de umidade elevada e temperatura alta durante todo o ano, pode comportar-se como perene, em razão do enraizamento progressivo de colmos decumbentes.

Não é o que acontece na região Sul do Brasil, onde a planta é anual. A infestação apresenta-se como um colchão sobre o solo, com altura de até $60 \mathrm{~cm}$. A massa vegetal formada não é muito grande, pois o "colchão" é poroso e leve (Kissmann, 1997).

A espécie prefere solos bem trabalhados e férteis, mas ocorre também em solos mais compactados e pobres. Suporta melhor os periodos de calor e seca do que as plantas anuais cultivadas e, nessas condições, domina lavouras. Ao iniciar-se a floração, há paralisação do desenvolvimento vegetativo, exceto das hastes florais. Efetuando-se cortes após o florescimento, podem ocorrer dois ou três surtos de florescimento durante uma temporada.

Após a maturação das sementes ocorre ainda certa dormência de pelo menos 45 dias. Mesmo após a quebra da dormência praticamente não ocorre germinação enquanto a temperatura se mantiver abaixo de $10{ }^{\circ} \mathrm{C}$; com temperaturas de 20 a $30^{\circ} \mathrm{C}$ há boa germinação. É geralmente a primeira infestante que começa a aparecer quando se transformam campos nativos em lavouras, nos Estados sulinos do Brasil (Kissmann, 1997).
D. ciliaris apresenta espiguetas binadas, lanceoladas, homomorfas, pubescentes, tricomas agudos e esbranquiçados presentes na gluma superior e lema inferior; gluma inferior de 0,2-0,3 mm, aguda; gluma superior de 1,2$1,8 \mathrm{~mm}$, aguda, $1 / 2$ a $3 / 4$ do comprimento da lema inferior, lema inferior de $(2,5)$ 2,9-3,3 $\mathrm{mm}$, agu$\mathrm{da}$, nervuras laterais glabras ou muito esparsamente escabras no ápice, glabra em ambos os lados da nervura central e alternadamente pubescentes e glabra nas demais regiões entre as nervuras, margens pilosas, tricomas não ultrapassando o ápice; antécio superior de $(2,5)$ 2,9-3,2 mm, castanho-claro na maturação (Canto-Dorow, 2001b).

$D$. ciliaris é muito próxima de $D$. sanguinalis, pelo hábito e inflorescência. Esta última diferencia-se principalmente por apresentar lema inferior com as nervuras laterais fortemente escabras em toda a extensão, além de lígula mais curta, com $0,8-1,0 \mathrm{~mm}$ de comprimento, bem como a gluma superior, que alcança até a metade do comprimento da lema inferior. Webster (1987) afirma que $D$. ciliaris e $D$. sanguinalis apresentam também distribuição geográfica distinta: a primeira ocorrendo em regiões tropicais de todo o mundo e a segunda restrita às regiões temperadas.

\section{- D. sanguinalis (L.) Scop.}

Trata-se de uma espécie cosmopolita, originalmente descrita para a América do Norte 
e sul da Europa, introduzida em várias partes do mundo. No Brasil, é citada para os Estados de São Paulo e Rio Grande do Sul. Habita geralmente solos arenosos, terrenos modificados, beira de estradas, campo pastoreado e hortas (Kissmann, 1997). Ela é mais freqüente apenas na região Sul do País (Dias, 2004). Podese verificar que $D$. sanguinalis é, na realidade, pouco comum em São Paulo, enquan to $D$. ciliaris é freqüente. Essa observação, aliada ao fato de que $D$. sanguinalis tem sido coletada no Rio Grande do Sul e em Santa Catarina, concorda com os dados de distribuição geográfica mencionados por Webster (1987).

Trata-se de uma planta anual reproduzida por semente. Após a maturação, as sementes geralmente apresentam um periodo inicial de dormência, após o qual, quando em condições adequadas de temperatura e umidade, podem germinar, havendo emergência desde $6 \mathrm{~cm}$ de profundidade. As sementes não necessitam de estímulo luminoso para a germinação. A partir do estádio de quatro folhas, inicia-se normalmente o perfilhamento, cuja intensidade depende do espaço disponivel e do período de luminosidade. Em condições ideais, podem ocorrer até 60 afilhos. Os colmos são geralmente decumbentes na porção inferior, podendo haver enraizamento a partir de nós em contato com o solo úmido. Efetuando-se o corte das plantas e sendo elas enterradas em seguida, como ocorre nas capinas, pode haver rebrotamento (Kissmann, 1997).

D. sanguinalis é tida como uma espécie de clima temperado, mas suporta bem temperatura mais elevada. Quando outras espécies de plantas, particularmente de culturas anuais, começam a sofrer por excesso de calor e seca, as diversas Digitarias, inclusive $D$. sanguinalis, tendem a dominar o terreno. Apresentam cromossomos $2 \mathrm{n}=18,34,36,48,54,70$ e 72 (Kissmann, 1997).

Esta espécie apresenta espigueta binadas, lanceoladas, homomorfas, pubescentes, tricomas agudos e esbranquiçados presentes na gluma superior e lema inferior; gluma inferior de 0,2-0,3 $\mathrm{mm}$, aguda; gluma superior de $1 \mathrm{~mm}$, obtusa, atingindo até a metade do comprimento da lema inferior; lema inferior de $(2,2) 3 \mathrm{~mm}$, aguda, nervuras laterais fortemente escabras, glabra em ambos os lados da nervura central e alternadamente pubescente e glabra nas demais regiões entre as nervuras, margens esparsamente pilosas, tricomas não ultrapassando o ápice; antécio superior de $(2,1)$ $2,9 \mathrm{~mm}$, castanho-claro na maturação (CantoDorow, 2001b).

\section{- D. bicornis (Lam.) Roem. \& Schult.}

Planta nativa no continente americano, ocorre ao sul dos Estados Unidos, América central e região Norte do Brasil, onde é a espécie de Digitaria mais freqüente. É uma planta anual reproduzida por sementes, apresentando 36 cromossomos $(n=36)$. Aprecia temperatura elevada e, por isso, ocorre principalmente em regiões quentes (Kissmann, 1997).

A planta assemelha-se à das demais Digitarias, sendo, contudo, de porte maior. Por seus colmos e ramos finos, é decumbente na parte inferior, com a parte superior ereta. Quando apoiada, pode chegar a 1,20 m de altura. Nas folhas, uma pilosidade geralmente ocorre apenas nas bainhas e na parte basal das lâminas (Kissmann, 1997).

Geralmente há 4-6 racemos com até $15 \mathrm{~cm}$ de comprimento na parte apical dos colmos, podendo também haver um verticilo inferior, com 4-6 racemos, e um superior entre eles, ocorrendo ou não racemos isolados (Kissmann, 1997).

$\mathrm{Na}$ parte inferior dos racemos encontrase um par de espiguetas homomorfas, com lemas glabras de nervuras eqüidistantes. As demais espiguetas ocorrem sempre em pares heteromorfos, sendo:

- uma espigueta subséssil, com nervuras eqüidistantes na lema estéril sem pêlos ou só levemente pubescentes; e

- uma espigueta pedicelada, com nervuras espaçadas irregularmente na lema estéril, apresentando pêlos entre as nervuras, exceto em ambos os lados da nervura mediana, e, quando madura, longos cílios a partir do espaço entre as nervuras externas e as margens, os quais se estendem lateralmente. A coloração das espiguetas maduras pode ser amarelada ou purpurescente (Kissmann, 1997).

D. bicornis apresenta espiguetas binadas, lanceoladas, heteromorfas, a pedicelada pilosa nas margens e alternadamente pilosa e glabra 
entre as nervuras laterais, a subséssil glabra ou esparsamente pilosa, tricomas agudos e esbranquiçados presentes na gluma superior e lema inferior, raramente espiguetas homomórficas; gluma inferior ausente ou reduzida, até $0,1 \mathrm{~mm}$, aguda; gluma superior de $2 \mathrm{~mm}$, aguda, $3 / 4$ do comprimento do lema inferior; lema inferior de 2,9-3,4 mm, agudo, nervuras laterais glabras, glabra em ambos os lados da nervura central, margens pilosas, estas geralmente com tricomas grossos e rígidos, não ultrapassando o ápice; antécio superior de 2,9$3,3 \mathrm{~mm}$, castanho claro na maturação (CantoDorow, 2001b).

\section{IMPLICAÇÕES SOBRE O MANEJO}

Atualmente, o principal método de controle das plantas daninhas na cultura da cana-deaçúcar é o químico, por meio da aplicação de herbicidas, tanto na condição de pré como de pós-emergência dessas plantas (Hernandez et al., 2001). Segundo Freitas et al. (2004), o controle químico de plantas daninhas em áreas de cana-de-açúcar é uma prática bastante difundida em todo o País. Assim, a compreensão da dinâmica populacional de espécies de plantas daninhas do gênero Digitaria (capimcolchão), bem como dos mecanismos de tolerância destas plantas daninhas a algumas classes de herbicidas, auxilia nas recomendações de manejo das plantas daninhas, evitando ou retardando o aparecimento do fenômeno de seleção de espécies tolerantes (Dias, 2004).

Os herbicidas mais recomendados para controle de Digitaria spp. na cultura da canade-açúcar, classificados de acordo com o mecanismo de ação em que atuam nas plantas, são: ametrina, diuron, tebuthiuron, metribuzin e diuron + hexazinone (inibidores do fotossistema II), isoxaflutole (inibidores da sintese de carbono), imazapic e imazapyr (inibidores de ALS), principalmente aplicados em pré-emergência (Lorenzi, 2000b; Andrei, 1999). No entanto, recentemente, tem-se observado falha no controle do capim-colchão em diversos campos de produção da cana-de-açúcar, onde os herbicidas dos grupos químicos das triazinas e uréias substituídas vinham sendo utilizados, de forma repetitiva, há vários anos. Essa aplicação repetitiva tem imposto uma pressão de seleção específica no gênero Digitaria, ou seja, as espécies deste gênero antes predominantes nas áreas da cana-de-açúcar, de alta suscetibilidade a esses herbicidas, foram sendo substituídas por outras de maior tolerância (Dias et al., 2003).

Lorenzi (2000b) relata que a espécie D. horizontalis é altamente suscetivel (mais de $95 \%$ de controle) aos herbicidas tebuthiuron, diuron + hexazinone, imazapic e imazapyr e suscetivel (85 a 95\% de controle) a ametrina, diuron e isoxaflutole. Ainda, considera a espécie $D$. sanguinalis altamente suscetivel ao diuron + hexazinone e suscetivel aos herbicidas ametrina e diuron. Esses resultados estão em concordância com os de Carvalho et al. (2005) e Hernandez et al. (2001), que relatam elevada suscetibilidade de $D$. horizontalis ao herbicida imazapic.

Por outro lado, em experimento realizado por Dias et al. (2005), os herbicidas pertencentes aos grupos químicos das imidazolinonas (imazapyr e imazapic) e uréias substituídas (diuron, tebuthiuron e diuron + hexazinone) não foram eficientes no controle de $D$. nuda. Já os herbicidas dos grupos químicos das triazinas (ametrina), triazinonas (metribuzin) e isoxazolinonas (isoxaflutole) foram aqueles que apresentaram os melhores niveis de controle para essa espécie. Embora ametrina, metribuzin, diuron e tebuthiuron tenham o mesmo mecanismo de ação, o sítio específico de ação desses herbicidas junto à quinona Qb é diferenciado (Christoffoleti et al., 2001). Portanto, essa pode ser a razão de ametrina e metribuzin com o mesmo mecanismo de ação (Pfister et al.,1981; Oettmeier et al., 1984) serem efetivos no controle de $D$. nuda e de diuron e tebuthiuron não o serem, pois seus sítios de ação provavelmente são diferentes. No caso da mistura diuron + hexazinone, apesar de o hexazinone ser uma triazinona, o diuron, que faz parte da mistura, não proporcionou o efeito aditivo no controle de $D$. nuda.

Christoffoleti et al. (2006) também realizaram trabalho com o objetivo de avaliar a eficácia de herbicidas sobre as espécies $D$. ciliaris e D. nuda. Os herbicidas testados foram $\left(\mathrm{g} \mathrm{ha}^{-1}\right)$ : mesotrione a 120; mesotrione a $120+$ ametrina a 2.000; trifloxysulfuron-sodium + ametrina a $32,4+1.280$; mesotrione a 120 + tryfloxysulfuron-sodium + ametrina a $32,4+1.280$; ametrina a 2.000; hexazinone + diuron a 264 
+ 936; mesotrione a $120+$ hexazinone + diuron a 264 + 936; metribuzin a 1.440 ; mesotrione a $120+$ metribuzin a 1.440 ; hexazinone + diuron a $264+936$ + MSMA a 960. Esses autores observaram que todos os tratamentos controlaram as espécies de capim-colchão, com exceção da mistura diuron + hexazinone sobre D. nuda, em campo e casa de vegetação.

A partir daí, pode-se observar que os herbicidas com os melhores niveis de controle para a espécie $D$. horizontalis (tebuthiuron, diuron + hexazinone, imazapic e imazapyr) foram aqueles menos efetivos no controle de $D$. nuda. Esse fato comprova a diferença da sensibilidade da espécie $D$. nuda aos herbicidas normalmente recomendados para controle de capim-colchão na cana-de-açúcar.

Existem pelo menos quatro mecanismos gerais que podem explicar a resistência e/ou tolerância de plantas daninhas a herbicidas e influenciar o modo de ação desses compostos: baixa concentração do herbicida no local de ação; menor absorção e/ou translocação do herbicida; maior metabolização e/ou detoxificação do herbicida a substâncias menos tóxicas (De Prado et al., 1990; Sherman et al., 1996); e perda de afinidade do herbicida pelo sítio de ação específico (Sherman et al., 1996).

Nesse sentido, Dias et al. (2003) desenvolveram trabalho sobre tolerância de espécies de capim-colchão aos herbicidas aplicados na cultura da cana-de-açúcar, avaliando aspectos de eficácia de herbicidas e estudo dos mecanismos de tolerância. Concluíram que a espécie $D$. nuda foi selecionada pela aplicação repetitiva dos herbicidas utilizados no controle de capim-colchão na cultura da cana-de-açúcar, demonstrando ser mais tolerante aos herbicidas dos grupos químicos das imidazolinonas e uréias substituídas, quando comparada a $D$. ciliaris. Neste trabalho também foi observado, por meio de curvas de dose-resposta, que $D$. nuda é mais tolerante que $D$. ciliaris aos herbicidas diuron, imazapyr e tebuthiuron. Em experimentos para determinar a absorção e translocação dos herbicidas diuron (via folha) e imazapyr e metribuzin (via raiz), pelas espécies $D$. ciliaris e $D$. nuda, o trabalho de Dias et al. (2003) demonstrou que a absorção e translocação não foram os mecanismos responsáveis pela tolerância apresentada por $D$. nuda aos herbicidas diuron e imazapyr.

Em ensaio conduzido em casa de vegetação por Dias et al. (2005), foi avaliada a eficácia dos diferentes herbicidas recomendados para a cultura da cana-de-açúcar no controle de quatro espécies de capim-colchão (D. ciliaris, $D$. nuda, $D$. horizontalis e $D$. bicornis), utilizando herbicidas em pré-emergência (g i.a. ha-1): ametrina a 2.500; diuron a 2.500; tryfloxys ulfuron-sodium + ametrin a a $32,4+1.280$; hexazinone + diuron a 264+936; tebuthiuron a 750 ; clomazone a 800 ; amicarbazone a 1.050; isoxaflutole a 112,5 e imazapic a 122,5 , além de testemunha sem aplicação, e também herbicidas aplicados em pós-emergência (g i.a. ha-1): mesotrione a 120, tryfloxysulfuron-sodium + ametrina a $32,4+1.280$; ametrina a 2.000; hexazinone + diuron a 264+936; metribuzin a 1.440; ametrina + clomazone a $1,5+1,0 ;$ MSMA a 1.920 ; e diuron a 2.500, além de testemunha sem aplicação.

Observou-se que os tratamentos hexazinone + diuron, tebuthiuron e imazapic apresentaram os menores controles para Digitaria nuda em pré-emergência, e os tratamentos diuron e hexazinone + diuron, os menores controles para Digitaria nuda em pós-emergência, o que a coloca como a espécie mais tolerante a estes herbicidas. As demais espécies demonstraram controle efetivo na maioria dos tratamentos, tanto em pré como em pós-emergência.

A espécie de capim-colchão $D$. nuda está sendo selecionada pela aplicação repetitiva dos herbicidas utilizados no controle desta planta daninha na cultura da cana-de-açúcar, caracterizando um processo de dinâmica populacional de mudança específica de plantas daninhas tolerantes a herbicidas. No entanto, alguns trabalhos precisam ser realizados com o objetivo de elucidar os possiveis mecanismos de tolerância a herbicidas que ocorrem em D. nuda, principalmente com relação à sensibilidade enzimática e ao metabolismo diferencial de compostos.

Assim, é importante que os produtores de cana-de-açúcar façam a identificação correta das espécies de capim-colchão em suas lavouras e utilizem estratégias de manejo objetivas para cada uma das espécies presentes na 
área. A identificação correta das espécies de capim-colchão nas lavouras de produção de cana-de-açúcar é importante principalmente para produtores tradicionais, que vêm utilizando o controle químico de plantas daninhas há muito tempo, de forma repetitiva e sem rotação de princípio ativo e mecanismo de ação dos herbicidas.

\section{LITERATURA CITADA}

ANDREI, E. (Ed.). Compêndio de defensivos agrícolas. São Paulo: Andrei, 1999. 672 p.

CANTO-DOROW, T. S. Digitarias do grupo "capimcolchão ou milhã" ocorrentes no Brasil. Disponível em: http://www.hrac-br.com.br. Acesso em: 15 abril de 2005.

CANTO-DOROW, T. S. Digitaria Heister ex Haller. In: WANDERLEY, M. G. L.; SHEPHERD, G. J.; GIULIETTI, A. M. (Ed.). Flora fanerogâmica do Estado de São Paulo. São Paulo: HUCITEC, 2001a. p. 143-150.

CANTO-DOROW, T. S. O gênero Digitaria Haller (Poaceae - Panicoideae - Poniceae) no Brasil. 2001b. 386 f. Tese (Doutorado em Fitotecnia) - Universidade Federal do Rio Grande do Sul, Porto Alegre, 2001.

CANTO-DOROW, T. S.; LONGHI-WAGNER, H. M. Novidades taxonômicas em Digitaria Haller (Poaceae) e novas citações para o gênero no Brasil. INSULA, v. 30, p. 21-34, 2001.

CARVALHO, S. J. P. et al. Curvas de dose-resposta para avaliação do controle de fluxos de emergência de plantas daninhas pelo herbicida imazapic. Planta Daninha, v. 23, n. 3 , p. 535-542, 2005

CAVALHEIRO, E. M.; BARRETO, I. L. As espécies indígenas ou espontâneas do gênero Digitaria, Heister ex Haller (Gramíneae) ocorrentes no Rio Grande do Sul. An. Técnico Inst. Pesq. Zoot. "Francisco Osório", v. 8, p. 171315, 1981.

CHRISTOFFOLETI, P. J. et al. Controle de plantas daninhas do gênero Digitaria através do uso do herbicida mesotrione, em pós-emergência, na cultura da cana-de-açúcar. In: CONGRESSO BRASILEIRO DA CIÊNCIA DAS PLANTAS DANINHAS, 25., 2006, Brasília. Resumos Expandidos... Brasília: SBCPD, 2006. CD-ROM.

CHRISTOFFOLETI, P. J.; CORTEZ, M. G.; MONQUEIRO, P. A. Bases da resistência de plantas daninhas aos herbicidas. In: SEMINÁRIO NACIONAL SOBRE MANEJO E CONTROLE DE PLANTAS DANINHAS EM PLANTIO DIRETO, 3., Passo Fundo, 2001. Resumos de Palestras... Passo Fundo: Aldeia Norte, 2001. p. 39-53.
CHRISTOFFOLETI, P. J. Resistência de plantas daninhas aos herbicidas inibidores da acetolactato sintase e acetil coenzima A carboxilase . 2000. $211 \mathrm{f}$. Tese (Livre-Docência) - Escola Superior de Agricultura "Luiz de Queiroz", Piracicaba, 2000.

CHRISTOFFOLETI, P. J.; CAETANO, R. S. X. Soil seed banks. Sci. Agríc., v. 55, p. 74-78, 1998.

De PRADO, P.; SCALLA, R.; GAILLARDON, P. Differential toxicity of simazine and diuron to Torrilis arvensis and Lollium rigidum. Weed Res., v. 30, p. 213-221, 1990.

DIAS, N. M. P.; CHRISTOFFOLETI, P. J.; TORNISIELO, V. L. Identificação taxonômica de espécies de capim-colchão infestantes da cana-de-açúcar no Estado de São Paulo e eficácia de herbicidas no controle de Digitaria nuda.

Bragantia, v. 64, n. 3, p. 389-396, 2005.

DIAS, A. C. R. et al. Eficácia agronômica de herbicidas pré e pós-emergência no controle de capim-colchão (D. ciliaris, $D$. nuda, D. horizontalis e D. bicornis) na cultura de cana-deaçúcar. In: CONGRESSO BRASILEIRO DA CIÊNCIA DAS PLANTAS DANINHAS, 25., Brasília, 2006. Resumos... Brasília: SBCPD/UnB/Embrapa Cerrados, 2006. p. 328.

DIAS, N. M. P. Tolerância de espécies de capim-colchão (Digitaria spp.) a herbicidas na cultura da cana-deaçúcar. 2004. 118 f. Tese (Doutorado em Fitotecnia) Escola Superior de Agricultura "Luiz de Queiroz", Piracicaba, 2004.

DIAS, N. M. P. et al. Absorção e translocação do herbicida diuron por espécies suscetível e tolerante de capim-colchão (Digitaria spp.). Planta Daninha, v. 21, n. 2, p. 293-300, 2003.

FNP - Consultoria e Comércio. Agrianual 2006: anuário de agricultura brasileira. São Paulo: 2006. p. 261-277.

FREITAS, S. P. et al. Controle químico de Rottboelia exaltata em cana-de-açúcar. Planta Daninha, v. 22, n. 3, p. 461-466, 2004.

HERNANDEZ, D. D.; ALVES, P. L. C. A.; MARTINS, J. V. F. Influência do resíduo de colheita de cana-de-açúcar sem queima sobre a eficiência do imazapic e imazapic + pendimethalin. Planta Daninha, v. 19, n. 3, p. 419-426, 2001.

KISSMANN, K. G. Plantas infestantes e nocivas - Tomo I: Plantas inferiores e monocotiledôneas. São Bernardo do Campo: BASF, 1997. 824 p.

KUVA, M. A. et al. Períodos de interferência das plantas daninhas na cultura da cana de açúcar. III - Capim-braquiária (Brachiaria decumbens) e capim-colonião (Panicum maximum). Planta Daninha, v. 21, n. 1, p. 37-44, 2003. 
LORENZI, H. Plantas daninhas do Brasil: terrestres e aquáticas. Nova Odessa: Instituto Plantarum, 2000a. 309 p.

LORENZI, H. Manual de identificação e de controle de plantas daninhas: plantio direto e convencional. Nova Odessa: Instituto Plantarum, 2000b. 339 p.

LORENZI, H. Plantas daninhas na cultura da cana-de-açúcar: plantas daninhas na lavoura do nordeste brasileiro. In: ENCONTRO TÉCNICO GOAL, CANA-DE-AÇÚCAR, 4., 1995, Recife. Anais... Recife: 1995.

LORENZI, H. Plantas daninhas e seu controle na cultura da cana-de-acúcar. SEMINÁRIO DE TECNOLOGIA AGRONỔMICA, 4., 1988, Piracicaba. Anais... São Paulo: COPERSUCAR, 1988. p. 281-301.

OETTMEIER, W. et al. Herbicide binding at photosystem II: a new azidotriazinonephotoaffinity label. Biochem.

Biophysics Acta, v. 767, p. 590-595, 1984.

OLIVEIRA JUNIOR, R. S.; CONSTANTIN, J. Plantas daninhas e seu manejo. Guaíba: Agropecuária, 2001. $362 \mathrm{p}$.
PFISTER, K. et al. Photoaffinity labeling of an herbicide receptor protein in chloroplast membranes. Proc. Nat. Acad. Sci. USA, v. 78, p. 981- 985, 1981.

PITELLI, R. A. Interferência das plantas daninhas em culturas agrícolas. Inf. Agropec., v. 11, n. 129, p. 16-27, 1985.

PROCÓPIO, S. O.; SILVA, A. A.; VARGAS, L. Manejo e controle de plantas daninhas em cana-de-açúcar. In.:

VARGAS, L.; ROMAN, E. S. (Eds.). Manual de manejo e controle de plantas daninhas. Bento Gonçalves: Embrapa Uva e Vinho, 2004. p. 397-452.

SHERMAN, T. D.; VAUGHH, K. C.; DUKE, S. O. Mechanism of action and resistance to herbicides. In: DUKE, S. O. (Ed.). Herbicide resistant crops. Boca Raton: CRC Press, 1996. p. 14-28.

VELDKAMP, J. F. A revision of Digitaria Haller (Gramineae) in Malasia. Blumea, v. 21, n. 1, p. 1-80, 1973.

WEBSTER, R. D.; HATCH, S. L. Taxonomy of Digitaria, section Aequiglumae (Poaceae-Paniceae). SIDA, v. 14, n. 2, p. 145-167, 1987. 